\title{
Cari Açık Belirleyicileri ve Sürdürülebilirlik Olasılığı İlişkisi: Türkiye
}

\author{
Çiğdem Karış ${ }^{\mathrm{a}, *}$ \\ ${ }^{a}$ Dr. Öğr. Üyesi, Trabzon Üniversitesi, Vakfikebir Meslek Yüksekokulu, 61400, Trabzon/Turkey \\ ORCID: 0000-0002-7534-0494
}

Relationship Between Current Deficit Definitions and Sustainability Probability: Turkey

\section{MAKALE BİLGISI}

Makale Geçmişi:

Başvuru tarihi: 18 Ekim 2019

Düzeltme tarihi: 13 Temmuz 2020

Kabul tarihi: 20 Temmuz 2020

\section{Anahtar Kelimeler:}

Cari İşlemler Açığı

Sürdürülebilirlik

Probit

\section{ARTICLE INFO}

\section{Article history:}

Received 18 October 2019

Received in revised form 13 July 2020

Accepted 20 July 2020

\section{Keywords:}

Current Account Deficit

Sustainability

Probit
ÖZ

Bu çalışma, Türkiye'de 1980-2018 döneminde cari işlemler açı̆̆ının belirleyicileri çerçevesinde sürdürülebilirlik olgusu üzerine olasılık tahminini içermektedir. Çalışmada cari açığın sürdürülebilirliği için genel ölçüt olarak kabul edilen cari işlemler açığı/GSYIH oranının bağımlı kukla değişken olarak ifade edilmesi durumunda cari açık belirleyicilerinin sürdürülebilirliği ne yönde etkilediğini tespit etmek amaçlanmıștır. Bu kapsamda oluşturulan regresyon modellerinde kullanılan bağımlı değişkenin nitel olması nedeniyle Probit analizinden faydalanılmıs ve değişkenlere ait marjinal etki hesaplamalarına da yer verilmiştir. Analiz sonucunda elde edilen bulgulara göre ortalama döviz kuru, M2 para arzı ve ihracatın ithalatı karşılama oranı değişkenleri dışındaki tüm değişkenlerde yaşanacak artışların cari açığın sürdürülebilirlik olasılığını negatif yönde etkilediği sonucuna ulaşılmıştır.

\section{A B S T R A C T}

This study includes the probability estimate on sustainability within the framework of the determinants of current account deficit in Turkey for the period 1980-2018. This study aims to determine how the current account deficit affects the sustainability of the current account deficit/GDP ratio, which is accepted as the general measure for the sustainability of the current account deficit. Due to the qualitative nature of the dependent variable used in the regression models, Probit analysis is used and the marginal effect calculations of the variables were also included. According to the results obtained from the analysis, the increases in all variables except average exchange rate, M2 money supply and export coverage ratio variables negatively affect the sustainability probability of the current account deficit.

\section{Giriş}

1990’lı yıllardan itibaren cari açığın sürdürülebilirliği ekonomik araştırmalar ve politik tartışmalar açısından odak noktası olmuştur. Sermaye hareketlerinin serbestleşmesi ve dış ticaretin önündeki engellerin ortadan kalkmasıyla uluslararası finans alanında cari açığın sürdürülebilirliği en çok tartışılan ve üzerinde durulan konulardan biri haline gelmiştir.

Cari işlemler dengesi, ülkeler açısından ekonomik karar alma sürecinde bir gösterge niteliği taşımakta olup makroekonomik istikrarın sağlanması açısından önem arz etmektedir. $\mathrm{Bu}$ noktada cari açığın sürdürülebilirliği makroekonomik istikrarın sağlanmasında gereklidir (Ayla ve Küçükkale, 2017: 1025). Sürdürülebilir bir cari açık istikrarlı bir durumu göstermekte olup ekonomi için bir sorun yaratmayacağını söylemek mümkündür. Yani sürdürülebilir bir cari açık dış borcun sürdürülebilirliği anlamına gelmektedir. Bu durumda, hükümetin sert politika değişiklikleri yapması ve yakın gelecekte uluslararası borçlarında temerrüde düşmesini gerektirecek bir durum yoktur. Ancak sürdürülemez kalıcı bir cari açık iç ve dış faiz oranlarında keskin bir yükselişe, döviz kurlarında hızlı bir değer kaybına, gelecek nesillere büyük bir borç yükleme ve daha düşük bir yaşam standardına neden olma gibi ciddi olumsuz etkiler meydana getirecektir. Şüphesiz ekonomide yaşanan bu tür olumsuzlukların da ani iç ve küresel bozulmaları tetikleyeceğini söylemek mümkündür.

Bir başka ifadeyle büyük ve kalıcı bir cari açık ülkelerin ekonomik refahlarına zarar verir ve dolayısıyla bu durum

\footnotetext{
** Sorumlu yazar/Corresponding author

e-posta: cigdemkaris@trabzon.edu.tr
} 
açıkların sürdürülebilirliği sorununu ortaya çıkarır. Sürekli olarak cari işlemler açığı veren bir ülke, yabancılara daha da borçlanacaktır. Cari işlemler açığının sürdürülebilirliği, büyük bir açığın ne zaman olacağı, bu açığın finanse edilmesi ve bu açığın yatırım için mi yoksa tüketim için mi kullanılacağının belirlenmesi gibi belirli özelliklere dayanmaktadır (Edwards, 2001)

Dış dengenin sağlanması noktasında önemli olan cari açığın iç dengeyi de bozması mümkündür. Cari açığın hem iç hem de dış denge üzerindeki bu etkisi makroekonomik açıdan sütlendiği rolü ortaya koymaktadır. $\mathrm{Bu}$ açığın finanse edilebilmesinde yaşanacak zorluklar ülkeleri darboğaza sokabilir. $\mathrm{Bu}$ noktada cari açığın ekonomiler üzerinde meydana getireceği etkide belirliyici olan etken açığın ne kadar süre sürdürülebildiğidir (Kim vd. 2009:16).

Cari açığın sürdürülebilirliğini tespit etmek için kullanılan kriterlerden yaygın olarak kullanılanların reel döviz kurunun değerlenmesi, brüt iç rezervler/borç stoku, sermaye girişlerinin büyüklüğü ve bileşimi, finansal yapı, ekonomik büyüme, borç yükü, döviz rezervleri ile dış borç/GSYH, cari açık/GSYH, ihracat/GSYH ve yatırım/tasarruf oranları olduğu görülmektedir (Ayla ve Küçükkale, 2018:56).

Bu çerçevede çalışmada Türkiye ekonomisinin 1980-2018 dönemine ait yıllık verilerle cari işlemler açığının belirleyicilerinin cari açı̆̆ın sürdürülebilirliğini ne yönde etkilediği probit analizi kullanarak tespit edilmesi amaçlanmıştır. Bu doğrultuda çalışmanın ilk kısmında konuya ilişkin genel bilgilere yer verildikten sonra ikinci kısımda literatürde söz konusu konuya ilişkin ilgili çalışmalar irdelenip özet halinde sunulmuştur. Üçüncü ve dördüncü kısımlarda ise ekonometrik yöntem ve veri seti tanıtılmış ve elde edilen bulgulara yer verilmiştir. Son kısımda ise elde edilen bulgular doğrultusunda çalışmanın sonuçları değerlendirilmiştir.

\section{Literatür Özeti}

Makroekonomik istikrarın sağlanması açısından önem arz eden cari açığın sürdürülebilirliği konusunda literatürde çok sayıda çalışma bulunmaktadır. Bu konuda yapılmış olan ilk çalışmalar arasında Husted(1992), Quintos(1995), MilesiFerretti ve Razin (1996), Wu, Fountas ve Chen(1996), Obstfeld ve Rogoff (1996), Fountas ve Wu (1999) ve Edwards (2001) yer almaktadır. Husted(1992), 1967:Q1 1989:Q4 dönemine ait üçer aylık verilerle ABD ekonomisi için yaptığı çalışmada serilerin eş bütünleşik olması ve eş bütünleşme katsayısının bire eşit olması durumunda cari açığın sürdürülebilir olduğunu gösterdiğini ortaya koymuştur. Quintos(1995), cari açığın sürdürülebilirliği açısından eş bütünleşme katsayısının bire eşit olmasının sağlam bir gösterge olduğunu ancak bu katsayının sıfir ile bir arasında bir değer taşıması durumunda zayıf da olsa cari açığın sürdürülebileceğini belirtmiştir.

Tablo 1'de cari açığın belirleyicileri sürdürülebilirliğine yönelik yapılan çalışmalardan elde edilen bulgular özet halinde sunulmuştur.

Tablo 1. Literatür Özeti

\begin{tabular}{|c|c|c|c|}
\hline Yazar/Yazarlar & Ülke/Dönem & Yöntem & Bulgular \\
\hline Wu, Fountas ve Chen(1996) & $\begin{array}{l}\text { ABD ve Kanada } \\
\text { /1973-1994 }\end{array}$ & Eş bütünleşme & $\begin{array}{l}\text { Cari açığın sürdürülemez olduğunu tespit } \\
\text { etmişlerdir }\end{array}$ \\
\hline Fountas ve Wu(1999) & ABD/1967/1994 & Engle-Granger eş bütünleşme & $\begin{array}{l}\text { İhracat ve ithalat serilerinin eş bütünleşik olmadığı } \\
\text { dolayısıyla cari açığın süründürülemez olduğu } \\
\text { belirtilmiştir }\end{array}$ \\
\hline Edwards (2001) & 149 ülke/1970-1997 & Probit modeli & $\begin{array}{l}\text { Cari açığın süründürülemez olduğunu ve bunun } \\
\text { ekonomik krizlere neden olduğunu tespit etmiştir }\end{array}$ \\
\hline Dülger ve Özdemir (2005) & G7 ülkeleri/1974-2001 & $\begin{array}{l}\text { SURADF panel ve oransal } \\
\text { birim kök testleri }\end{array}$ & $\begin{array}{l}\text { Japonya, Almanya, ABD ve İngiltere'de cari açığın } \\
\text { sürdürelemez nitelikte olduğu, buna karşın Kanada, } \\
\text { İtalya ve Fransa'da cari açığın sürdürülebilir olduğu } \\
\text { bulunmuştur }\end{array}$ \\
\hline Yücel ve Yanar (2005) & Türkiye/1964-2003 & Engle-Granger eş bütünleşme & $\begin{array}{l}\text { Cari açığın sürdürülemez olduğunu ortaya } \\
\text { koymuşlardır. }\end{array}$ \\
\hline Aristovnik (2006) & $\begin{array}{l}\text { Doğu Avrupa ve eski } \\
\text { Sovyetler Birliği } \\
\text { ülkeleri/1992-2006 }\end{array}$ & Dinamik panel GMM & $\begin{array}{l}\text { Ekonomik büyüme, bütçe açığı ve dışa açıklık } \\
\text { oranının cari açı̆̆ı artırdığı bulunmuştur }\end{array}$ \\
\hline Aristovnik (2007) & $\begin{array}{l}17 \text { Ortadoğu ve Kuzey Afrika } \\
\text { ülkesi/1971-2005 }\end{array}$ & Panel GMM & $\begin{array}{l}\text { Ekonomik büyüme oranı, kamu harcamaları, dışa } \\
\text { açıklık oranı, doğrudan yabancı sermaye } \\
\text { yatırımlarının cari işlemler açığını artırdığı tespit } \\
\text { edilmiştir }\end{array}$ \\
\hline $\begin{array}{l}\text { Lau, Baharumshah ve Haw } \\
\text { (2006) }\end{array}$ & $\begin{array}{l}\text { Tayland, Kore, Filipinler, } \\
\text { Malezya ve } \\
\text { Endonezya/1976:1-2001:4 }\end{array}$ & $\begin{array}{l}\text { Tek değişkenli birim kök } \\
\text { testi }\end{array}$ & $\begin{array}{l}\text { Cari açı̆̆ın kriz öncesi dönemde sürüdürülebilirken } \\
\text { kriz sonrası dönemde sürdürülemez olduğunu tespit } \\
\text { etmişlerdir }\end{array}$ \\
\hline $\begin{array}{l}\text { Chu, Chang, Chang, Su ve } \\
\text { Yuan (2007) }\end{array}$ & 48 Afrika ülkesi/1980-2004 & Panel veri analizi & $\begin{array}{l}37 \text { ülkede cari açığın sürdürülebilir nitelikte olduğu } \\
\text { ortaya konmuştur }\end{array}$ \\
\hline Gruber ve Kamin (2007) & 61 ülke/1982-2003 & Panel veri analizi & $\begin{array}{l}\text { Kişi başına düşen milli gelir, bütçe dengesi, yabancı } \\
\text { sermaye girişleri ve petrol fiyatlarının bu ülkelerde } \\
\text { cari açığı artırdığ } 1 \text { sonucuna ulaşıllmıştır }\end{array}$ \\
\hline Yamak ve Korkmaz (2007) & Türkiye/2001:4-2005:9 & Sinır testi & $\begin{array}{l}\text { Cari açığın sürdürülebilirliğinin zayıf formda } \\
\text { olduğu tespit edilmiştir }\end{array}$ \\
\hline Perera ve Verma (2008) & Sri Lanka/1950-2006 & Eş bütünleşme & $\begin{array}{l}\text { Cari açığın sürdürülemez nitelikte olmadığ } \\
\text { bulunmuştur }\end{array}$ \\
\hline $\begin{array}{l}\text { İsmail ve Baharumshah } \\
(\mathbf{2 0 0 8 )}\end{array}$ & Malezya/1960-2004 & $\begin{array}{l}\text { Granger nedensellik testi ve } \\
\text { eş bütünleşme yöntemi ile } \\
\text { VAR analizi }\end{array}$ & 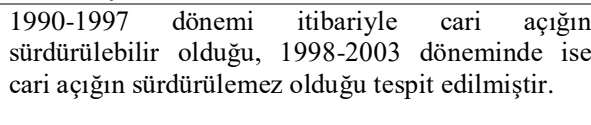 \\
\hline Berke (2009) & Türkiye/1989:1-2006:2 & Parçalı eş bütünleşme & $\begin{array}{l}\text { Uzun dönemde reel ihracat ve reel birleşik ithalat } \\
\text { serilerinin parçalı eş bütünleşik olduğu, bundan }\end{array}$ \\
\hline
\end{tabular}




\begin{tabular}{lll}
\hline & & \\
\hline & & \\
Erdoğan ve Bozkurt (2009) & Türkiye/1990:01-2008:10 & MGARCH \\
\hline ABD ve İngiltere/1960-2008 & $\begin{array}{l}\text { Doğrusal olmayan zaman } \\
\text { Kanada/1961-2008 yöntemleri }\end{array}$ \\
\hline Holmes vd. (2011) & Fransa/1978-2008 & GLS ve VEC \\
\hline Polat (2011) & Türkistane/2000-2010 & ARDL sinır testi \\
\hline Bajo-Rubio (2012) & İspanya/1850-2000 & Regresyon analizi \\
\hline $\begin{array}{l}\text { Trachanas ve Katrakilidis } \\
\text { (2013) }\end{array}$ & $\begin{array}{l}\text { Portekiz, İrlanda, İtalya, } \\
\text { Yunanistan, İtalya/1971-2009 }\end{array}$ & Eş bütünleşme \\
\hline
\end{tabular}

hareketle uzun dönemde cari açığın süründürülebilir olduğu sonucuna ulaşılmıștır

İhracatın ithalatı karşılama oranının cari açıkla en yüksek ilișkiye sahip olduğu ve cari açıkla aralarındaki ilişkinin negatif olduğu, petrol fiyatlarının ise ikinci yüksek ilişkiye sahip olduğu ve cari açıkla pozitif ilişkili olduğu bulunmuştur

Tüm ülkelerde cari açığın sürdürülemez olduğu bulunmuştur Cari açığın sürdürülebilir olduğu tespit edilmiştir Cari açığın sürdürülebilirliğinin düşük düzeyde olduğu tespit edilmiştir

Cari açığın sürdürülebilir olduğu sonucuna ulaşılmıştır

Bütçe açığının cari açığa neden olduğu bulgusuna ulaşılmıştır

Cari açığın düsük düzeyde sürdürülebilir olduğu bulunmuştur. Ayrıca cari işlemler açığının en öneli nedenlerinin; enerji ithalatı, diş ticaret açığı, doğrudan yabancı yatırımları ve portföy yatırımlarının kâr transferleri ve dış borç stoku olduğu bulunmuștur

Uluslararası faiz oranlarında yaşanacak yavaş bir yükselmenin Türkiye'de cari açığı zayıf bir etkiyle sürdürülemez durumdan sürdürülebilir duruma dönüştüreceği tespit edilmiştir.

Doğrusal olmayan zaman serisi yöntemleri

Engle-Granger Eşbütünleșme Cari açığın sürdürülebilirliğinin zayıf düzeyde ve DOLS yöntemi olduğunu ortaya koymuşlardır

Tüm değișkenler arasında uzun dönemli bir ilișki olduğu dış borç, döviz kuru ve enflasyon ile cari açık arasında pozitif bir ilişkinin, para arzı ile cari açık arasında ise negatif bir ilişkinin olduğu bulgularına ulaşılmıştır

Cari açığın en önemli belirleyicilerinin tasarrufyatırım açığı, bütçe açığı, ihracatın ithalatı karşılama oranı (dış ticaret açığı), ekonomik büyüme, reel döviz kuru, faiz oranı, enflasyon ve petrol fiyatları olduğu tespit edilmiştir

15 OECD ülkesinde uzun dönemde cari açı̆̆ın sürdürülebilirliğinin güçlü formda kısa dönemde ise zayıf formda olduğu tespit edilmiștir

İhracat ve doğrudan yabancı yatırımlar ile cari açık arasında pozitif yönlü, döviz kuru, M2 para arzı, petrol fiyatları ve enflasyon ile cari açık arasında negatif yönlü bir ilişki olduğu sonucuna ulaşılmıştır

\section{Yöntem}

Çalışmada cari işlemler açığının sürdürülebilir olup olmadığı kapsamında oluşturulan bağımlı değişkenin "sürdürülebilir" ve "sürdürülemez" şeklinde nitel olarak ifade edilmesi Probit analizinin tercih edilmesinin temel sebebini oluşturmuştur. Zira literatürde yer alan ekonomik değişkenlere yönelik nitel araştırmalarda logit ve doğrusal olasılık yöntemine kıyasla probit analizinin tercih edildiği de bilinmektedir. $\mathrm{Bu}$ nedenle normal birikimli dağılım fonksiyonunun kullanıldığı probit modelinin analiz için uygun olduğuna karar verilmiştir.

Probit regresyon analizi, bağımlı değişkenin kategorik nitelikte olması durumunda tercih edilebilen, doğrusal olmayan ve gözlemlenemeyen bir fayda endeksi açıklamasını içermektedir. Başka bir ifadeyle, bağımsız değişkene bağlı olarak belirlenen bir endeks tahminlemesini öngörmektedir. Bu çerçevede gerçekleşme olasıllı̆̆ tahmin edilen bağımlı değişkeninin açıklanma gücü bahsedilen fayda endeksinin büyüklüğüne göre belirlenmektedir (Akın, 2002: 38). Analize başlamadan önce bağımsız değişkenlerin durağanlık mertebelerinin belirlenmesi önem arz etmektedir (Cebeci, 2012: 139).

Probit fonksiyonunun doğrusal olmaması nedeniyle normal birikimli dağılım fonksiyonunun tersi alınarak doğrusallaştırma işlemi yapılmalıdır. $\mathrm{Bu}$ kapsamda birikimli olasılık fonksiyonunu ifade eden $F$, stokastik değişken olan $\mathrm{X}$ değişkeni ve varyans değeri "1" ortalaması "0" olan normal dağıllımlı bir tesadüfî "s" değişkeni kullanılarak şu işlemler yapılmaktadır (Güriş ve Çağlayan, 2005: 685):

$$
\begin{gathered}
P_{i}=F\left(\beta_{0}+\beta_{1} X_{i}\right)=F\left(Z_{i}\right) \\
P_{i}=F\left(Z_{i}\right)=\frac{1}{\sqrt{2 \pi}} \int_{-\infty}^{Z_{i}} e^{-s^{2} / 2 d s} \\
Z_{i}=F^{-1}\left(P_{i}\right)=\beta_{0}+\beta_{1} X_{i}
\end{gathered}
$$

(1), (2), (3) nolu denklemlerde ifade edilen " $Z_{i}$ " parametresi, fayda indeksi tahminini göstermektedir. Başka bir ifadeyle, $P_{i}$ ve herhangi bir gerçek değerin standart normal değişkenin $\beta_{0}+\beta_{1} X_{i}$ değerinden küçük olma olasılı̆̆ını içermektedir (Güriş ve Çağlayan, 2005: 685). Bununla birlikte oluşturulan probit modelin bağımsız değişkenlerin bağımlı değişken üzerindeki etki katsayılarını içermemesi değişkenlerin marjinal etki hesaplamalarının yapılmasını gerektirmektedir. 


\section{Araştırma Bulguları}

Bu çalışma Türkiye ekonomisinin 1980-2018 döneminde gerçekleşen cari işlemler açığının sürdürülebilir olup olmadığını ifade eden Cari Açı/GSYIH oranı ile açığı belirleyen çeşitli değişkenler arasındaki ilişkinin yıllık veriler ve olasılık tahmini kullanılarak incelenmesini öngörmektedir. Araştırmada öncelikle Cari Açı/GSYIH oranı hesaplanmış, açığın literatürde genel kabul görmüş olan \%5 eşik değeri aştığı dönemler dikkate alınarak sürdürülebilirliği ifade eden bağımlı kukla değişken türetilmiştir. Kukla değişken oluşturulurken yorumsal ifadelerin daha açıklayıcı olmasını temin etmek amacıyla ilgili oranın eşik değerin altında kaldığı yıllarda " 1 ” ve eșik değeri aştığı yıllarda ise "0" değerinin kullanılması tercih edilmiştir. Çalışmanın amacı gereği cari işlemler açığını belirleyen değişkenlerin açığın sürdürülebilir olma olasılığı üzerindeki etkisi Probit analizi yardımıyla sınanmıştır. Kullanılan veri seti ise Worldbank, TÜIK, OPEC ve TCMB veri tabanından temin edilmiş olup analiz için gerekli dönüşümler yapılarak logaritma alma ve standartlaştırma işlemleri gerçekleştirilmiștir. Söz konusu veri setine ait tanımlamalar ve istatistiki değerler Tablo 2'de sunulmuştur.

Tablo 1. Veri Seti ve İstatistiki Göstergeler

\begin{tabular}{|c|c|c|c|c|c|c|}
\hline \multicolumn{2}{|c|}{ VERILERR } & \multicolumn{5}{|c|}{ AÇIKLAMA } \\
\hline \multicolumn{2}{|c|}{ CA } & \multicolumn{5}{|c|}{ Cari işlemler açığı /GSYİH kukla değişkeni } \\
\hline \multicolumn{2}{|c|}{ LYT } & \multicolumn{5}{|c|}{ Logaritmik yurtiçi tasarruf (Tl) } \\
\hline \multicolumn{2}{|c|}{ FO } & \multicolumn{5}{|c|}{ Mevduat faiz oranı $(\%)$} \\
\hline \multicolumn{2}{|c|}{ SBD } & \multicolumn{5}{|c|}{ Bütçe dengesi (TL) (standardize) } \\
\hline \multicolumn{2}{|c|}{ DAO } & \multicolumn{5}{|c|}{ Dişa açıklık oranı (\%) } \\
\hline \multicolumn{2}{|c|}{ LDK } & \multicolumn{5}{|c|}{ Logaritmik ortalama döviz kuru (Tl) } \\
\hline \multicolumn{2}{|c|}{ LM2 } & \multicolumn{5}{|c|}{ Logaritmik m2 para arzı $(\mathrm{Tl})$} \\
\hline \multicolumn{2}{|c|}{ KO } & \multicolumn{5}{|c|}{ İhracatın ithalatı karşılama oranı (\%) } \\
\hline \multicolumn{2}{|c|}{ LDB } & \multicolumn{5}{|c|}{ Logaritmik brüt dış borç stoku (Tl) } \\
\hline \multicolumn{2}{|c|}{ LPF } & \multicolumn{5}{|c|}{ Logaritmik ortalama ham petrol varil fiyatı $(\mathrm{Tl})$} \\
\hline \multicolumn{7}{|c|}{ İstatistiki Göstergeler } \\
\hline LYT & & 25.755 & 0.941 & 23.921 & 27.556 & $0.931(0.6278)$ \\
\hline FO & & 0.413 & 0.243 & 0.080 & 0.878 & $3.290(0.1929)$ \\
\hline SBD & & -4.555 & 1.000 & -3.047 & 0.800 & $\begin{array}{c}9.713 \\
(0.0078) \\
\end{array}$ \\
\hline DAO & & 0.336 & 0.086 & 0.157 & 0.510 & $1.70(0.4278)$ \\
\hline LDK & 39 & 0.930 & 0.630 & 0.010 & 2.150 & $\begin{array}{c}3.497 \\
(0.1740) \\
\end{array}$ \\
\hline LM2 & & 15.425 & 4.846 & 6.829 & 21.986 & $\begin{array}{c}3.908 \\
(0.1417) \\
\end{array}$ \\
\hline $\mathrm{KO}$ & & 0.641 & 0.085 & 0.368 & 0.814 & $5.700(0.0579)$ \\
\hline LDB & & 26.287 & 1.050 & 23.788 & 28.399 & $0.454(0.7968)$ \\
\hline LPF & & 4.453 & 0.733 & 2.870 & 5.820 & $1.551(0.4606)$ \\
\hline
\end{tabular}

Analizin bağımsız değișkenlerini olușturacak olan serilerin grafiksel gösterimleri ise Grafik 1'de belirtilmiştir.
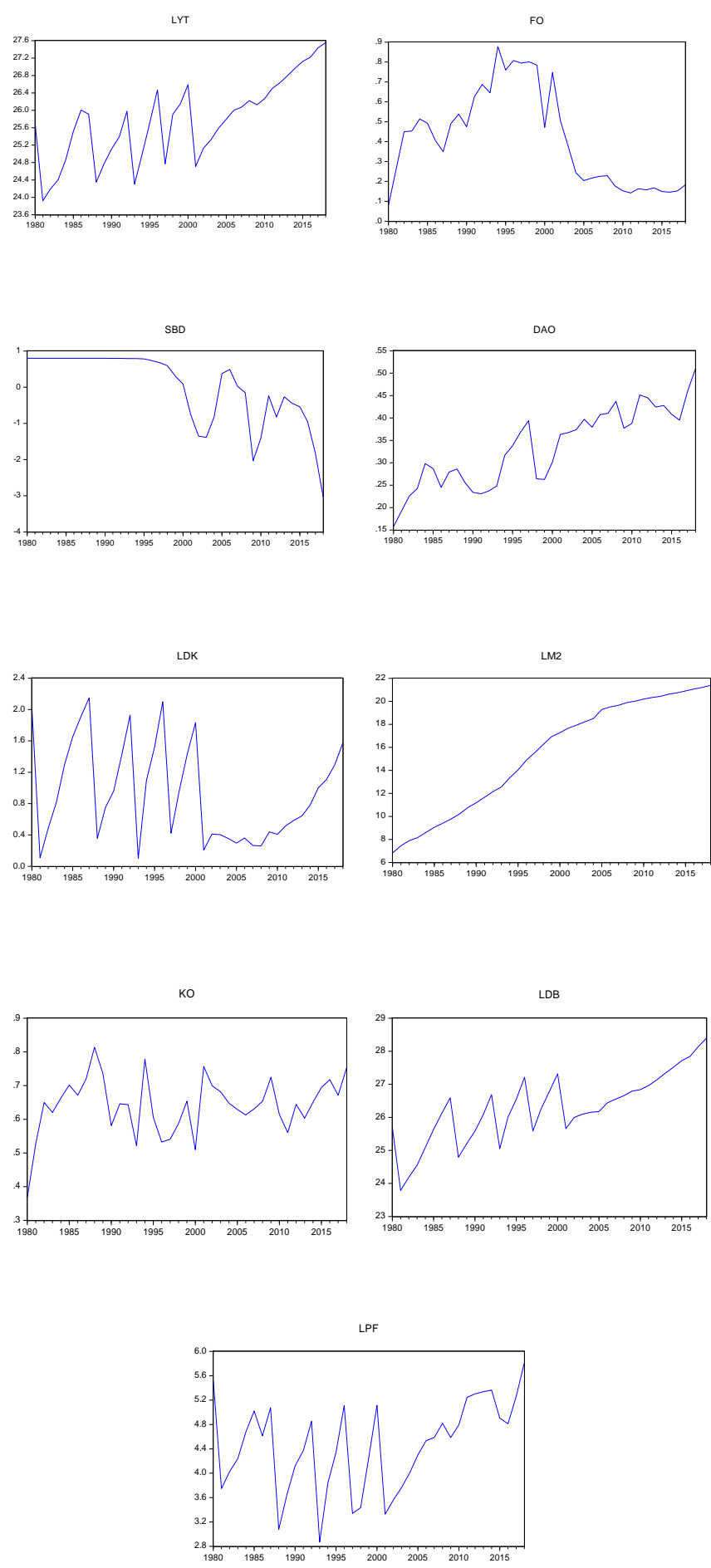

Grafik 1. Değişkenlerin Grafiksel Gösterimleri

Analize başlamadan önce serilerin durağanlık seviyeleri ADF (Genişletilmiş Dickey-Fuller) testi ile Akaike (AIC) bilgi kriteri kullanılarak belirlenmiş ve ilgili sonuçlar Tablo 3 'de özetlenmiştir. 
Tablo 2. Durağanlık Testi Sonuçları

\begin{tabular}{|c|c|c|c|c|c|c|}
\hline \multirow[b]{2}{*}{ 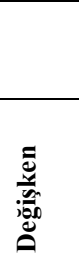 } & \multicolumn{2}{|c|}{ ADF (Sabitsiz) } & \multicolumn{2}{|c|}{ ADF (Sabitli) } & \multicolumn{2}{|c|}{$\begin{array}{c}\text { ADF (Sabitli ve } \\
\text { Trendli) }\end{array}$} \\
\hline & : & 亡 & : & 亡 & ⿸\zh14巳一⿻ & - \\
\hline LYT & $\begin{array}{c}1.827 \\
(0.981)\end{array}$ & $\begin{array}{c}-6.494 \\
(0.000)\end{array}$ & $\begin{array}{l}-0.398 \\
(0.898)\end{array}$ & $\begin{array}{c}-6.977 \\
(0.000)\end{array}$ & $\begin{array}{l}-2.006 \\
(0.578)\end{array}$ & $\begin{array}{c}-6.907 \\
(0.000)\end{array}$ \\
\hline FO & $\begin{array}{l}-1.040 \\
(0.263)\end{array}$ & $\begin{array}{c}-3.121 \\
(0.002)\end{array}$ & $\begin{array}{l}-1.090 \\
(0.708)\end{array}$ & $\begin{array}{l}-7.645 \\
(0.000)\end{array}$ & $\begin{array}{l}-1.827 \\
(0.668)\end{array}$ & $\begin{array}{c}-7.888 \\
(0.000)\end{array}$ \\
\hline SBD & $\begin{array}{c}0.062 \\
(0.695)\end{array}$ & - & $\begin{array}{c}0.320 \\
(0.976)\end{array}$ & - & $\begin{array}{l}-3.813 \\
(0.027)\end{array}$ & - \\
\hline DAO & $\begin{array}{c}2.763 \\
(0.997)\end{array}$ & - & $\begin{array}{l}-1.465 \\
(0.540)\end{array}$ & - & $\begin{array}{l}-4.116 \\
(0.013)\end{array}$ & - \\
\hline LDK & $\begin{array}{l}-0.307 \\
(0.567)\end{array}$ & $\begin{array}{c}-6.817 \\
(0.000)\end{array}$ & $\begin{array}{l}-1.549 \\
(0.497)\end{array}$ & $\begin{array}{l}-6.729 \\
(0.000)\end{array}$ & $\begin{array}{l}-1.635 \\
(0.758)\end{array}$ & $\begin{array}{r}-6.638 \\
(0.000)\end{array}$ \\
\hline LM2 & $\begin{array}{c}0.499 \\
(0.818)\end{array}$ & $\begin{array}{c}-1.150 \\
(0.223)\end{array}$ & $\begin{array}{l}-1.628 \\
(0.458)\end{array}$ & $\begin{array}{l}-1.627 \\
(0.458)\end{array}$ & $\begin{array}{c}0.095 \\
(0.996)\end{array}$ & $\begin{array}{c}-3.357 \\
(0.073)\end{array}$ \\
\hline KO & $\begin{array}{c}0.361 \\
(0.783)\end{array}$ & - & $\begin{array}{c}-5.490 \\
(0.0001)\end{array}$ & - & $\begin{array}{c}-5.383 \\
(0.0004)\end{array}$ & - \\
\hline LDR & $\begin{array}{c}2.837 \\
(0.998)\end{array}$ & - & $\begin{array}{c}-1.588 \\
(0.477)\end{array}$ & - & $\begin{array}{l}-5.047 \\
(0.001)\end{array}$ & - \\
\hline LDB & $\begin{array}{c}2.274 \\
(0.993)\end{array}$ & $\begin{array}{l}-2.705 \\
(0.008)\end{array}$ & $\begin{array}{l}-0.780 \\
(0.812)\end{array}$ & $\begin{array}{c}-6.904 \\
(0.000)\end{array}$ & $\begin{array}{l}-2.186 \\
(0.482)\end{array}$ & $\begin{array}{c}-6.791 \\
(0.000)\end{array}$ \\
\hline $\mathbf{L P F}$ & $\begin{array}{c}0.573 \\
(0.835)\end{array}$ & $\begin{array}{l}-7.415 \\
(0.000)\end{array}$ & $\begin{array}{c}-0.802 \\
(0.806)\end{array}$ & $\begin{array}{l}-5.635 \\
(0.000)\end{array}$ & $\begin{array}{l}-1.641 \\
(0.755)\end{array}$ & $\begin{array}{c}-5.846 \\
(0.0002)\end{array}$ \\
\hline
\end{tabular}

Tablo 3'deözetlenen bulgulara göre LYT, FO, LDK, LM2, LDB ve LPF serilerinin fark durağan, diğer serilerin ise seviyesinde durağan olduğu tespit edilmiştir. Fark durağan olduğu tespit edilen serilerden sadece LM2 serisinin \%10 anlamlılık düzeyinde olduğu görülmektedir. $\mathrm{Bu}$ belirlemenin ardından çeşitli kombinasyonlar denenerek probit çözümlemeleri yapılmış ve ilgili model çözümlemelerinde Quadratic Hill Climbing algoritması ile Huber-White kriterinden faydalanılmıştır. Çalışılan probit modellerinden çoklu doğrusal bağıntı hatası vermeyen ve istatistiki olarak anlamlı olan üç temel regresyon tespit edilmiştir. Bu kapsamda elde edilen modeller ve ilgili tahmin sonuçları aşağıdaki şekildedir.

Tablo 4. Model 1 Tahmin Sonuçları

\begin{tabular}{|c|c|c|c|c|c|}
\hline 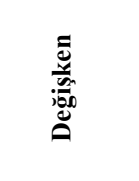 & 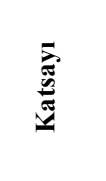 & 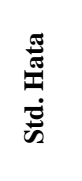 & .0 & $\begin{array}{l}\frac{y}{\bar{E}} \\
\frac{\bar{\sigma}}{\tilde{\sigma}}\end{array}$ & 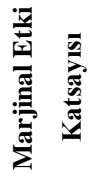 \\
\hline $\mathbf{C}$ & -20.477 & 5.801 & -3.530 & 0.0004 & - \\
\hline LM2 & 13.959 & 4.302 & 3.245 & 0.0012 & 0.196 \\
\hline LYT & -1.274 & 0.371 & -3.434 & 0.0006 & -0.017 \\
\hline KO & 27.767 & 7.869 & 3.529 & 0.0004 & 0.391 \\
\hline FO & -11.555 & 3.341 & -3.458 & 0.0005 & -0.162 \\
\hline$\underset{\text { İstatistiği }}{\text { LR }}$ & $\begin{array}{c}26.976 \\
(0.00)\end{array}$ & \multicolumn{3}{|c|}{ Wald F-İstatistiği } & $\begin{array}{l}3.9873 \\
(0.009)\end{array}$ \\
\hline $\begin{array}{c}\text { McFadden } \\
\mathbf{R}^{2}\end{array}$ & 0.690 & \multirow{2}{*}{\multicolumn{3}{|c|}{ LM Test }} & 1.792 \\
\hline $\begin{array}{c}\text { Log } \\
\text { likelihood }\end{array}$ & -6.068 & & & & \\
\hline
\end{tabular}

Tablo 5. Model 2 Tahmin Sonuçları

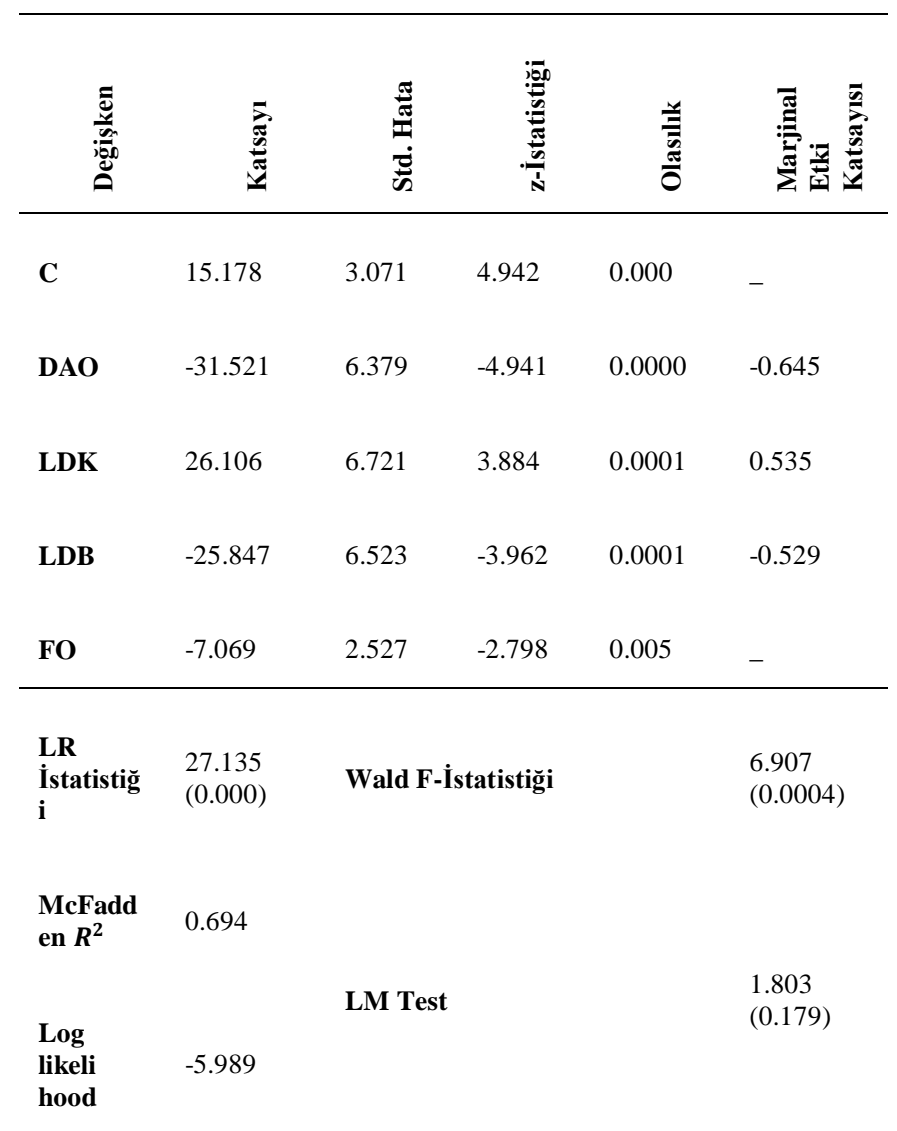

Tablo 6. Model 3 Tahmin Sonuçları

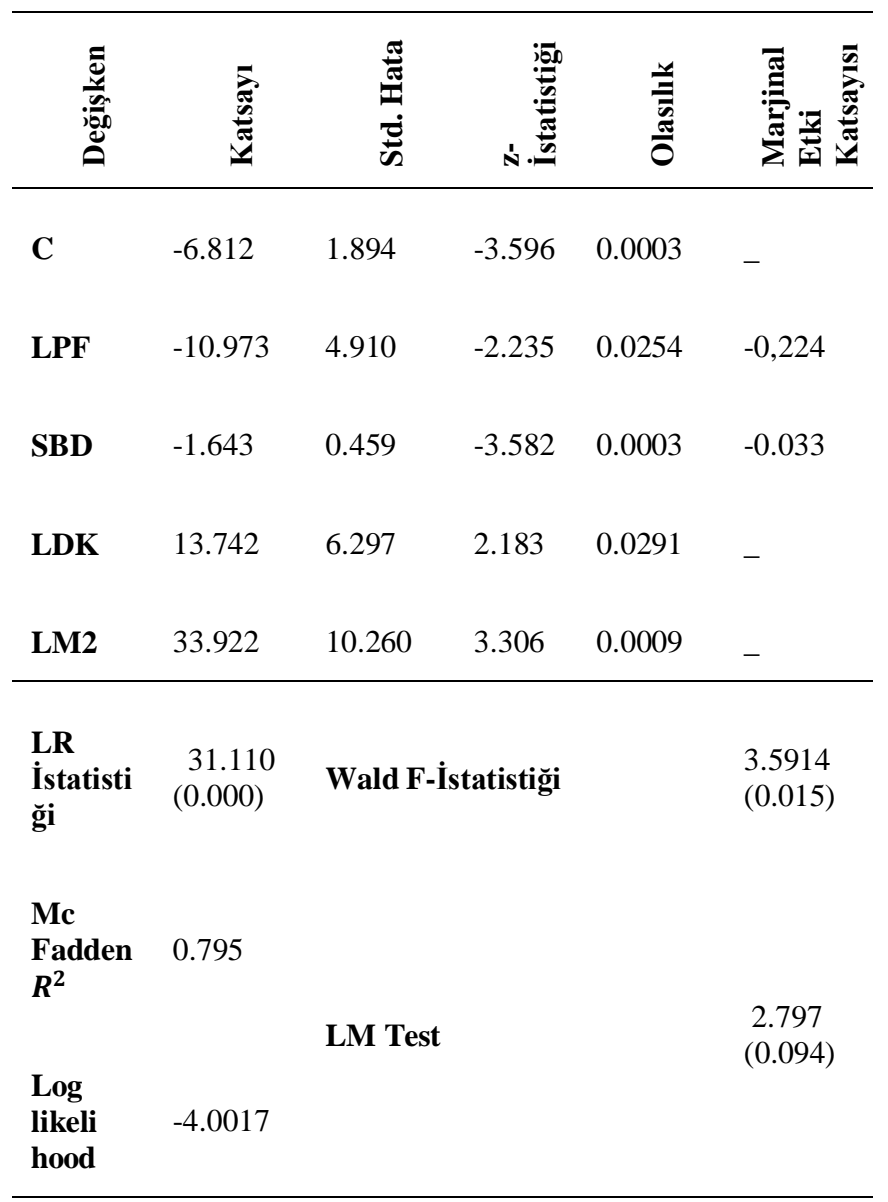


Uygulanan probit model tahminlerinde öngörülen sonuçlara göre modellerin açıklama gücünü ifade eden ve 0 ile 1 arasında bir değer alabilen Mc Fadden $\boldsymbol{R}^{\mathbf{2}}$ değerlerinin yeterli olduğu belirlenmiştir. Wald testi ile de değişkenlerin bütünsel olarak anlamlı olduğu tespit edilmiştir. Ayrıca sabit terim dişındaki değişken katsayılarının anlamlılık sınaması için kullanılan LR istatistiği sonuçları modellerin uyum iyiliğinin $\% 1$ düzeyinde istatistiki olarak anlaml olduğunu göstermektedir. Bununla birlikte Davidson ve MacKinnon (1993)'a ait yapay regresyon modelinde olduğu gibi varyans sınaması amaciyla kullanılan LM testine ait sonuçlar tüm modeller için anlamlı bulunmuştur. Söz konusu sınama işleminde ilgili modelde sabit varyans olduğunu ifade eden $\mathrm{H}_{0}$ hipotezi tüm modeller için kabul edilmiştir

Analiz sonuçları cari açığın sürdürülebilir olma olasılığı ile LDK, LM2 ve KO değişkenleri arasında pozitif; LYT, FO, SBD, DAO, LDB ve LPF değişkenleri arasında ise negatif yönlü bir ilişki olduğunu göstermiştir. Söz konusu sonuçlara göre, döviz kurunda azalma yaşanması durumunda ulusal paranın değer kazanmasına bağlı olarak dış ticaret açığı ve dolayısıyla cari açı artışı gözlenebilecektir. $\mathrm{Bu}$ durum cari açığın sürdürülebilirlik olasılığının azalmasına sebep olabilir. Para arzında gözlenen azalmalar ise faiz oranını arttırarak yatırımların azalmasına sebep olabileceği gibi nakit sıkışıklığı nedeniyle durgunlaşan piyasa cari açığın sürdürülebilirlik olasılığını negatif yönde etkileyebilecektir. İhracatın ithalatı karşılama oranında gözlenen azalmalar da döviz kuruna benzer bir mekanizma ile sürdürülebilirlik üzerinde olumsuz etki yaratabilecektir. Diğer taraftan yurtiçi tasarruflar ve sürdürülebilirlik olasılığı arasında negatif olarak tespit edilen ilişki teorik beklentilere aykırıdır. Ancak bu durum yurtiçi tasarrufların cari açık yerine borçların finanse edilmesi amacıyla kullanılması ile açıklanabilecektir. Faiz oranlarında yaşanan artışlar ise üretimin azalmasına ve dışa bağımlılık da dikkate alındığında cari açı̆̆ın artmasına neden olabileceğinden sürdürülebilirliği negatif yönde etkileyebilecektir. Ayrıca bütçe açıklarının artması halinde ortaya çıkabilecek olan "ikiz açık" olgusu teorik beklentilere de uygun şekilde cari açığın sürdürülebilirlik olasılığı üzerinde negatif yönde etkili olacaktır. Benzer şekilde dışa açıklık oranında yaşanan artışlar da teorik beklentilere uygun şekilde cari açığın sürdürülebilirlik olasılığı üzerinde negatif etkiler yaratabilir. Bununla birlikte dış borç artışlarının ülkenin döviz giderinin artması anlamına geldiği düşünüldüğünde cari açı̆̆ın sürdürülebilirliğinin tehlikeye girmesi olasıdır. Son olarak petrol fiyatı artışlarının ithalat artışı ile birlikte sürdürülebilirlik üzerinde negatif yönde etki yaratması beklenebilecek bir olgudur.

Çalışmada probit analizi yardımıyla tespit edilen yön ilişkisi dışında marjinal etki hesaplamaları ile değişkenlerin cari açığın sürdürülebilir olma olasılığını ifade eden kukla değişken üzerindeki etkisi de hesaplanmıştır. Söz konusu modellerde ortak değişken kullanılmasının sebebi daha çok değişken için sonuca ulaşabilmektir. Dolayısıyla ortak değişkenler için marjinal etki hesaplaması tekrarlanmamıştır. Buna göre LDK, LM2 ve KO değişkenlerinin incelenen referans döneminde azalma göstermesi cari açığın sürdürülebilirlik olasılığını sırasıyla $\% 53, \% 20$ ve $\% 39$ düzeyinde azaltmaktadır. Bununla birlikte analiz sonucunda LYT, FO, SBD, DAO, LDB ve
LPF değişkenlerinde yaşanan artışların ise cari açığın sürdürülebilir olma olasılığını sırasıyla $\% 2, \% 16, \% 3, \% 65$, $\% 53$ ve \%22 oranında azalttığı tespit edilmiştir.

\section{Sonuç ve Öneriler}

Özellikle gelişmekte olan ülke ekonomileri için gittikçe artan bir öneme sahip olan cari işlemler dengesinin sürdürülebilir olup olmadığı makroekonomik istikrarın temin edilmesi açısından oldukça önem arz eden bir konudur. Zira günümüzde pek çok ülke cari açık sorunu ile mücadele etmekte ve konuya ilişkin gerek mali gerekse yapısal düzenlemelerle çeşitli uygulamalara yer vermektedir. Öngörülen düzenlemelerin genel çerçevesine bakıldığında ise açığın varlığından ziyade sürdürülebilir olmasının gerekliliği üzerinde durulduğu görülmektedir.

$\mathrm{Bu}$ çerçevede hazırlanan çalışma Türkiye'nin 1980 yılından günümüze kadar olan süreçte temel sorunlarından biri haline gelen cari işlemler açı̆̆ı probleminin sürdürülebilir olma niteliği açısından etkili olabilecek değişkenler üzerine olup 1980-2018 döneminde, cari açık üzerinde etkili olan çeşitli faktörler ile sürdürülebilirlik arasındaki ilişkinin olasılık tahminini içermektedir. Probit regresyon modelinin kullanıldığı bu çalışma değişkenlerin marjinal etki hesaplamalarını da kapsayacak şekilde planlanmıştır. $\mathrm{Bu}$ bağlamda cebirsel olarak hesaplanan marjinal etki değerleri, probit modellerinde kullanılan bağımsız değişkenlerde oluşacak artış ya da azalışların sürdürülebilirlik olasılığını nasıl etkileyebileceğini ifade eden katsayı değerleridir.

Analiz sonucunda ortalama döviz kuru, para arzi ve ihracatın ithalatı karşılama oranında yaşanacak azalmaların cari açığın sürdürülebilirlik olasılığını azaltabileceği belirlenmiştir. Analizden elde edilen bu bulgular Erdoğan ve Bozkurt (2009), Çakır ve Sözen (2016) ve Bozgeyik ve Kutlu (2019)'un çalışmasından elde ettiği sonucu desteklemektedir. Bu kapsamda ortalama döviz kuru ve karşılama oranında yaşanacak azalmalar ithalatı pozitif, ihracatı negatif yönde etkileyerek cari açığın sürdürülebilirlik olasılığını azaltabilecektir. Para arzında yaşanan azalmalar ise faiz oranını yükselterek yatırımları negatif etkileyecek ve yaşanan nakit sıkışıklığı da piyasada durgunluğa sebep olursa cari açığın finansmanı güçleşebilecektir.

Araştırma sonuçları kapsamında ulaşılan bulgulara göre cari açığın sürdürülebilirlik olasılığındaki azalmalar yurtiçi tasarruf, mevduat faiz oranı, bütçe açığı, dışa açıklık oranı, brüt dış borç stoku ve ortalama ham petrol varil fiyatlarında gözlenen artışlardan kaynaklanabilmektedir. Analizden elde edilen bu bulgular Erdoğan ve Bozkurt (2009), Aristovnik (2006), (2007), Gruber ve Kamin (2007), Trachanas ve Katrakilidis (2013), Altunöz (2014), Çakır ve Sözen (2016), Karagöl ve Erdoğan (2017)'nin çalışmalarındaki sonuçları desteklemektedir. Buna göre cari açı̆̆ın önemli finansman kaynaklarından biri olarak görülen yurtiçi tasarruflar ile sürdürülebilirlik olasılığı ilişkisinin negatif bulunması teorik beklentilere uygun olmamakla birlikte Türkiye örneğinde tasarrufların borçların finansmanında kullanılması ile izah edilebilecektir. Analiz sonucunda mevduat faiz oranları ve dişa açıklık oranında yaşanan artışların sürdürülebilirlik olasılığı üzerinde negatif etkiler yaratacağı ise teorik beklentilere uygundur. Bütçe açığı değerlendirildiğinde ise sürekli açık veren Türkiye 
ekonomisi bütçesindeki açıkta gözlenen artışların ikiz açık nedeniyle sürdürülebilirlik olasılığını azaltması beklenen bir sonuçtur. Ayrıca dış borç stokunda yaşanan artışlar teorik beklentilere uygun şekilde döviz giderine sebep olacağından sürdürülebilirlik olasılığını güçleştirebilecektir. Son olarak petrol fiyatlarında yaşanan artışların ithalat kanalıyla negatif etki yaratması ise beklenen bir sonuçtur.

Marjinal etki hesaplamalarından elde edilen sonuçlara göre döviz kuru, dışa açıklık oranı ve dış borç stokunun cari açığın sürdürülebilirlik olasılığını arttırma gücünün yüksek olması bu değişkenlerin Türkiye için belirleyici olduğuna işaret etmektedir. $\mathrm{Bu}$ noktada özellikle son zamanlarda oldukça hareketli olan döviz piyasasının stabilize edilmesinin son derece önemli olduğunu söylemek mümkündür. Ayrıca dışa açıklığın ithalat lehine geliştiği Türkiye ekonomisinde ithal ikame stratejisinin selektif olarak uygulanmasına yönelik politikaların arttırılması önerilebilir. Bununla birlikte dış borç yükünün azaltılması ve ödeme planları bağlamında ekonomik etkinliğin temin edilmesinin öneminin arttığını söylemek mümkündür.

\section{Kaynakça}

Akçayır, Ö., \& Albeni, M. (2016). Türkiye'de Kronikleşen Cari Açıkların Sürdürülebilirlik Analizi. Siyaset, Ekonomi ve Yönetim Araştırmaları Dergisi, 4(3), 35-62.

Akın, F. (2002). Ekonometri, Bursa: Beta Basım.

Altunöz U. (2014). Cari Açık Sorunun Temel Nedenleri ve Sürdürülebilirliği: Türkiye Örneği. İstanbul Gelişim Üniversitesi Sosyal Bilimler Dergisi, 1 (2), 115-132.

Aristovnik, A. (2006). The Determinants \& Excessiveness of Current Account Deficits in Eastern Europe \& the Former Soviet Union. The William Davidson Institute Working Paper, The University of Michigan, (827), 1-27.

Aristovnik, A. (2007). Short and Medium Term Determinants of Current Account Balances in Middle East and North Africa Countries. The William Davidson Institute Working Paper, The University of Michigan, (862), 1-24.

Ayla, D. \& Küçükkale, Y. (2017). Cari Açıkların Sürdürülebilirliği: Bir Derleme. Atatürk Üniversitesi Sosyal Bilimler Enstitüsü Dergisi, 21(3), 1025-1041.

Ayla, D. \& Küçükkale, Y. (2018). Cari Açıkların Sürdürülebilirliği: Literatür Taraması. Karadeniz Sosyal Bilimler Dergisi, 10(18), 55-80.

Berke, B. (2009). Türkiye'de Cari Açığın Sürdürülebilirliği: Parçalı Eşbütünleşme Analizi. Akdeniz Üniversitesi IIBF Dergisi, 9(18), 117-145.

Bajo-Rubio, O. (2012). The Balance-Of-Payments Constraint on Economic Growth in a Long-Term Perspective: Spain, 1850-2000. Explorations in Economic History, 49(1), 105-117.
Bozgeyik, Y., \& Kutlu, A. (2019). Türkiye'de Cari Açı̆̆ın Belirleyicileri: 1992-2017 Dönemi. Maliye Dergisi, Ocak-Haziran, 176, 1-26.

Cebeci, İ. (2012). Krizleri İncelemede Kullanılan Nitel Tercih Modelleri: Türkiye İçin Bir Probit Model Uygulamas1 (1988-2009). İstanbul Üniversitesi İktisat Fakültesi Mecmuası, 62(1),127-146.

Chen, S.-W. (2010). Testing for The Sustainability of The Current Account Deficit in Four Industrial Countries: A Revisitation. Economics Bulletin, 30(2), 1-21

Chu, H.-P., Chang, T., Chang, H.-L., Su, C.-W., \& Yuan, Y. (2007). Mean Reversion in The Current Account of Forty-Eight African Countries: Evidence From The Panel Suradf Test. Physica, A(384), 485-492.

Çakır, B., \& Sözen, İ. (2016). Türkiye'de Cari İşlemler Dengesini Etkileyen Finansal Değişkenlerin Var Analizi. The Academic Elegance, 3(5), 19-42.

Davidson, R., \& MacKinnon, J.G. (1993). Estimation and Inference in Econometrics, New York: Oxford University Press.

Dülger, F., \& Özdemir, Z. A. (2005). Current Account Sustainability in Seven Developed Countries. Journal of Economic and Social Research, 7(2), 47-80

Edwards, S. (2001). Does The Current Account Matter?. NBER Working Paper, (8275), 1-69.

Ekinci, R. \& Kahyaoğlu,H. (2015).The Sustainability of Current Account Deficit in Turkey: A Non-Linear Time Series Approach. Izmir Review of Social Sciences, 2(2), 27-40, January.

Erdoğan, S., \& Bozkurt, H. (2009). Türkiye'de Cari Açığın Belirleyicileri: MGARCH Modelleri ile Bir İnceleme. Maliye Finans Yazllarl, 1(84), 135-172.

Fountas, S., \& Wu, J.-L. (1999). Are the U.S. Current Account Deficits Really Sustainable? International Economic Journal, 13(3), 51-58.

Gruber, J. W., \& Kamin, S. B. (2007). Explaining the Global Pattern of Current Account Imbalances. Journal of International Money and Finance, 26, $500-522$

Güriş, S., \& Çağlayan, E. (2005). Ekonometri ve Temel Kavramlar, İstanbul: Der Yayınları.

Holmes, M. J., Panagiotidis T., \& Sharma, A. (2011). The Sustainability of India's Current Account. The Rimini Centre for Economic Analysis WP (41-07), $1-28$.

Husted, S. (1992). The Emerging U.S. Current Account Deficit in The 1980s: A Cointegration Analysis. The Review of Economics and Statics, 74(1), 159. 166.

İsmail, H. B., \& Baharumshah, A. Z. (2008). Malaysia's Current Account Deficits: An İntertemporal Optimization Perspective. Empirical Economics, 35(3), 569-590. 
Karagöl, V., \& Erdoğan, M. (2017). Türkiye Ekonomisinde Cari Açığın Belirleyicileri ve Cari Açığa Yönelik Politika Uygulamaları. Ulakbilge, 5(10), 353-381.

Kim, B.-H., Min, H.-G., Hwang, Y.-S., \& McDonald, J. A. (2009). Are Asian Countries Current Accounts Sustainable? Deficit, Even When Associated With High İnvestment, Are Not Costless. Journal of Policy Modelling, 31, 163-179.

Lau, E., Baharumshah, A. Z., \& Haw, C. T. (2006). Current Account: Mean-Reverting or Random Walk Behavior?. Japan and The World Economy, 18, 90-107.

Milesi-Ferretti, G. M., \& Razin, A. (1996). Current Account Sustainability.Princeton Studies in International Finance, 81, 1-78.

Obstfeld, M., \& Rogoff, K. (1996). Foundations Of International Macroeconomics, MIT Press.

Öztürk, S., \& Çoltu, S. (2018). Seçilmiş OECD Ülkelerinde Cari Açığın Sürdürülebilirliği Analizi. Bingöl Üniversitesi Sosyal Bilimler Enstitüsü Dergisi, 8(16), 37-48.

Perera, N., \& Verma, R. (2008). An Empirical Analysis of Sustainability of Trade Deficit: Evidence From Sri Lanka. International Journal of Applied
Econometrics and Quantivative Studies, 5(1), 7992.

Polat, Ö. (2011). Sustainability of The Current Account Deficit in Turkey. African Journal of Business Management, 5(2), 577-581.

Quintos, C. E. (1995). Sustainability of The Deficit Process With Structural Shifts. Journal of Business and Economic Statistics, 13(4), 409-417.

Trachanas, E., \& Katrakilidis, C. (2013). The Dynamic Linkages Offiscal and Current Account Deficits: New Evidence from Five Highly Indebted European Countries Accounting for Regime Shifts and Asymmetries. Economic Modelling, 31, 502510.

Wu, J.-L., Fountas, S., \& Chen, S.-L. (1996). Testing For The Sustainability of The Current Account Deficit in Two Industrial Countries. Economics Letters, (52), 193-198.

Yamak, R., \& Korkmaz, A. (2007). Türk Cari İşlemler Açığı Sürdürülebilir mi? Ekonometrik Bir Yaklaşım. Bankacılar Dergisi, (60), 17-32.

Yücel, F., \& Yanar, R. (2005). Türkiye'de Cari İşlemler Açıkları Sürdürülebilir mi? Zaman Serileri Perspektifinden Bir Bakış. Ç. $\ddot{U}$. Sosyal Bilimler Enstitüsü Dergisi, 14(2), 483- 492. 